\title{
Infant brain structures, executive function, and attention deficit/hyperactivity problems at preschool age. A prospective study
}

\begin{abstract}
Akhgar Ghassabian, ${ }^{1,2}$ Catherine M. Herba, ${ }^{3,4}$ Sabine J. Roza, ${ }^{2,5}$ Paul Govaert, ${ }^{6}$ Jacqueline J. Schenk, ${ }^{7}$ Vincent W. Jaddoe, ${ }^{8,9}$ Albert Hofman, ${ }^{8}$ Tonya White, ${ }^{2,10}$ Frank C. Verhulst, ${ }^{2}$ and Henning Tiemeier ${ }^{2,5,8}$

${ }^{1}$ The Generation R Study Group, Erasmus MC; ${ }^{2}$ Department of Child and Adolescent Psychiatry, Erasmus MC-Sophia Children's Hospital, Rotterdam, the Netherlands; ${ }^{3}$ Department of Psychology, Université du Québec à Montréal; ${ }^{4}$ Ste-Justine's Hospital Research Centre, Montréal, Canada; ${ }^{5}$ Department of Psychiatry, Erasmus MC, Rotterdam, the Netherlands; ${ }^{6}$ Neonatology, Erasmus MC-Sophia Children's Hospital, MC, Rotterdam, the Netherlands; ${ }^{7}$ Erasmus School of Pedagogical Sciences, Erasmus University; ${ }^{8}$ Epidemiology, Erasmus MC, Rotterdam, the Netherlands; ${ }^{9}$ Paediatrics, Erasmus MC-Sophia Children's Hospital, Rotterdam, the Netherlands; ${ }^{10}$ Radiology,
\end{abstract} Erasmus MC, Rotterdam, the Netherlands

\begin{abstract}
Background: Neuroimaging findings have provided evidence for a relation between variations in brain structures and Attention Deficit/Hyperactivity Disorder (ADHD). However, longitudinal neuroimaging studies are typically confined to children who have already been diagnosed with ADHD. In a populationbased study, we aimed to characterize the prospective association between brain structures measured during infancy and executive function and attention deficit/hyperactivity problems assessed at preschool age. Methods: In the Generation R Study, the corpus callosum length, the gangliothalamic ovoid diameter (encompassing the basal ganglia and thalamus), and the ventricular volume were measured in 784 6-week-old children using cranial postnatal ultrasounds. Parents rated executive functioning at 4 years using the Behavior Rating Inventory of Executive Function-Preschool Version in five dimensions: inhibition, shifting, emotional control, working memory, and planning/organizing. Attention Deficit/Hyperactivity Problems were assessed at ages 3 and 5 years using the Child Behavior Checklist. Results: A smaller corpus callosum length during infancy was associated with greater deficits in executive functioning at 4 years. This was accounted for by higher problem scores on inhibition and emotional control. The corpus callosum length during infancy did not predict Attention Deficit/ Hyperactivity Problem at 3 and 5 years, when controlling for the confounders. We did not find any relation between gangliothalamic ovoid diameter and executive function or Attention Deficit/Hyperactivity Problem. Conclusions: Variations in brain structures detectible in infants predicted subtle impairments in inhibition and emotional control. However, in this population-based study, we could not demonstrate that early structural brain variations precede symptoms of ADHD. Keywords: Brain, corpus callosum, executive function, Attention Deficit/Hyperactivity Disorder.
\end{abstract}

\section{Introduction}

Neuroimaging studies have provided evidence for a relation between variations in brain structures and neuropsychiatric disorders in children (Hendren, De Backer, \& Pandina, 2000). In children with Attention Deficit/Hyperactivity Disorder (ADHD), various morphological changes have been reported in brain structures such as the thalamus (Ivanov et al., 2010), striatum (Castellanos et al., 1996), ventricular volumes (Castellanos et al., 1996), right prefrontal

Conflict of interest statement: The first phase of Generation $R$ was supported by Erasmus Medical Centre Rotterdam, the Erasmus University Rotterdam, and the Netherlands Organization for Health Research and Development (ZonMw 10.000.1003). Dr. Frank C. Verhulst is the contributing editor of the Achenbach System of Empirically Based Assessment, from which he receives remuneration. For the other authors, no competing financial interest exists. cortex (Rubia, 2005), and the corpus callosum (Hutchinson, Mathias, \& Banich, 2008). Recently, longitudinal magnetic resonance imaging (MRI) studies showed that growth trajectories of anterior corpus callosum were different in adolescents with ADHD, indicating anomalies in developmental brain trajectories in these children (Gilliam et al., 2011). Few studies investigated the morphological variations in brain structures related to ADHD symptoms in normally developing children (Ducharme, et al., 2012). However, most prospective neuroimaging studies are confined to children who have already been diagnosed with ADHD.

Neuropsychological assessments of children with ADHD show that some have deficits in the metacognitive processes that control behavior, known as executive functioning (Willcutt, Doyle, Nigg, Faraone, \& Pennington, 2005). Although not a sufficient factor, executive dysfunction is an important 
component of the complex psychopathology underlying ADHD. Prospective neuroimaging studies of premature infants with white matter abnormalities followed until school age showed that executive function was affected even in the absence of ADHD (Woodward, Clark, Pritchard, Anderson, \& Inder, 2011). However, it remains unclear whether, within the general population, brain structural variations can be detected in infants who will show symptoms of executive dysfunction or ADHD later in life.

To elucidate whether brain structural differences precede psychopathology, we need neuroimaging studies of very young children free of behavioral problems. If brain structural differences precede symptoms of ADHD, children at risk for ADHD could be identified during infancy. In early childhood, the brain has a great plasticity and myelination is in progress (Yakovlev \& Lecours, 1967). Therefore, any intervention in that sensitive period could be more effective. Within this context, our goal was to characterize the prospective relation of variations in brain structures during infancy with executive function and attention deficit/hyperactivity problems assessed at preschool age. We measured the following brain structures using cranial ultrasounds at approximately 7 weeks of postnatal life: the corpus callosum length, the gangliothalamic ovoid diameter (encompassing the basal ganglia and thalamus), and the cerebral ventricular volume. The choice of brain structures was based on anatomical abnormalities reported in ADHD children and specific functions of brain structures. The corpus callosum is the largest white matter structure with a role of interhemisphere connectivity (Clark, Boutros, $\&$ Mendez, 2010). The size of corpus callosum may reflect the topographically connected cortical area relevant for higher order cognitive function or a more efficient interhemispheric information transfer (Santhouse et al., 2002). Basal ganglia have a role in disinhibition and planning and are partially involved in the regulation of attention and cognitive function (Clark et al., 2010). Forming cortico-striato-thalamo-cortical loops, thalamus is involved in behavior regulation (Kimura, Minamimoto, Matsumoto, \& Hori, 2004). The cerebral ventricular volume has been associated with fetal maturation during gestation, and is a general parameter of global brain development (Gilmore et al., 1998). We hypothesized that the variations in the above-mentioned brain structures, which have been shown in children with ADHD, may already exist during infancy.

\section{Methods \\ Participants}

The present study was embedded within the Generation $\mathrm{R}$ Study, a population-based cohort from fetal life onward in Rotterdam, the Netherlands (Jaddoe et al., 2010). A subsample of 1106 children and their parents were assessed in detail postnatally. The eligibility criterion was Dutch ethnicity, defined as four grandparents born in the Netherlands, to exclude the confounding or effect modification by ethnicity. This study received approval from the Medical Ethics Committee of the Erasmus Medical Centre, Rotterdam. Written informed consent was obtained from all participating parents and anonymity was guaranteed.

Approximately at 7 weeks, 904 (of 1106) neonates and their parents visited the research center for detailed postnatal assessments. Because of potential differences in brain development of fetuses born to multiple and singleton pregnancies, we excluded 10 twin pairs. Of the remaining $(n=884)$, we obtained ultrasound images with sufficient quality of one or more structures in 784 infants. Follow-up information on executive function was available in 655 children (83.5\%). The corresponding numbers for Attention Deficit/Hyperactivity Problems at 3 and 5 years were $667(85.1 \%)$ and $649(82.8 \%)$, respectively.

\section{Cranial ultrasound measurements}

Postnatal cranial ultrasounds were performed in infants at the age of $6.8 \pm 1.9$ weeks (age range: 3.620.7 weeks) using a commercially available multifrequency electronic transducer $(3.7-9.3 \mathrm{MHz})$ with a scan angle of $146^{\circ}$, usable for three-dimensional volume acquisition (Voluson 730 Expert; GE Healthcare, Waukesha, WI). The details of ultrasound measurements have been described previously (Herba et al., 2010; Roza et al., 2008). The probe was positioned on the anterior fontanel and a volume box was placed at the level of the foramen of Monro in a symmetrical coronal section. A pyramid-shaped volume of the brain tissue was scanned and the diameter of brain structures were measured offline. Two raters, trained by a neonatologist with expertise in neonatal cranial ultrasound imaging (P.G.), independently measured every image. Raters also coded the quality of the ultrasound image on a three-point scale, based on the ability to clearly delineate the boundaries of the structures. We excluded images with a quality rating of zero by both raters.

In the best midsagittal view, we defined the corpus callosum length as the largest diameter from rostrum to splenium (see Figure 1). Commonly, the thickness of

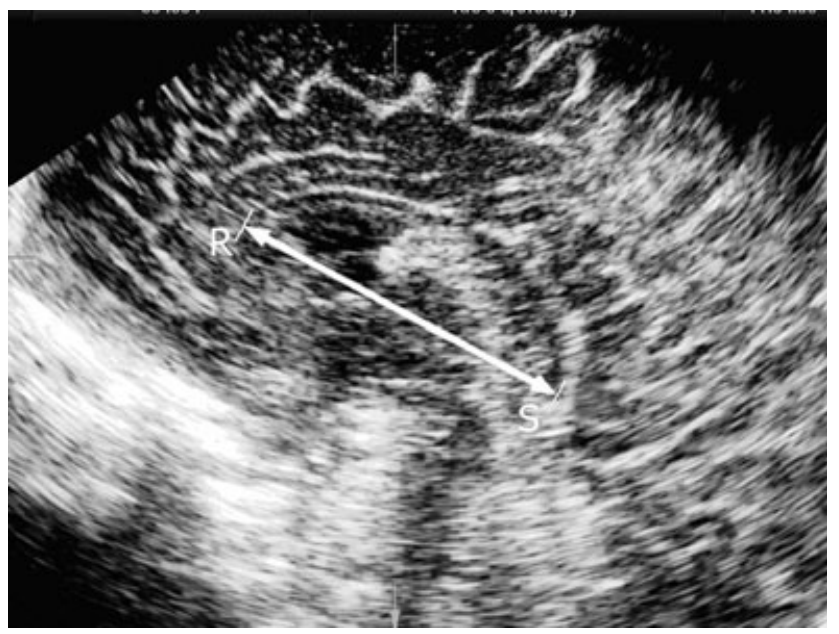

Figure 1 The corpus callosum length. The largest diameter was measured from rostum (R) to splenium (S). 
corpus callosum, as measured by MRI, is used in neuroimaging studies (Stewart et al., 1999). However, with ultrasound techniques variations in the thickness of corpus callosum cannot be reliably measured (Anderson et al., 2004). Therefore, we used the measurement along the entire body of the corpus callosum and obtained an average corpus callosum length using measurements from the two raters. The interrater reliability of the corpus callosum length was good [Cronbach's $\alpha=.85$ and, IntraClass Coefficient $(\mathrm{ICC})=.85]$.

The gangliothalamic ovoid diameter encompassed the following structures: basal ganglia (caudate nucleus, putamen, and globus pallidus) and thalamus. Further details about the boundaries of these structures have been described previously (Naidich, Gusnard, \& Yousefzadeh, 1985; Naidich, Yousefzadeh, Gusnard, \& Naidich, 1986). The gangliothalamic ovoid is readily identified using ultrasound technology, largely because a parasagittal standard section through lateral ventricular and deep gray nuclei is reproducibly found. The interrater reliability of right and left gangliothalamic ovoid diameter was good (Cronbach's $\alpha=.80$ and, ICC $=.80$ ).

To measure the ventricular system, the volume of the ventricular frontal horns, ventricular body, and trigone on both sides was quantified in milliliters. Further details about the measurement of ventricular system have been described elsewhere (Roza et al., 2008). Four raters manually traced the left and right cerebral ventricles using a mouse driven cursor. Across the four raters, ICC for the right and left ventricle varied between .989.993 and .992-.997, respectively.

\section{Executive functioning}

When the children were 4.0 years $(S D=1.0$ month), the Behavior Rating Inventory of Executive Function-Preschool Version (BRIEF-P) was used to measure executive functioning (Gioia, Espy, \& Isquith, 2003). The BRIEF-P is a parent-completed questionnaire to assess executive function behaviors in a broad age range of preschoolers. It contains 63 items within five related but nonoverlapping theoretically and empirically derived clinical scales that measure children's ability in different aspects of executive functioning: inhibition (16 items), to stop his-her own behavior; shifting (10 items), to change focus from one mindset to another; emotional control (10 items), to modulate emotional responses; working memory (17 items), to hold information in mind to complete a task; planning/organization (10 items), to manage a current and future-oriented task demands within the situational context.

A sum score (the Global Executive Composite) can be derived by adding the scores of five domains. The clinical raw scores and the composite scores yield $T$ scores based on gender and age. Higher scores indicate more problems with executive functioning.

The BRIEF-P measures executive functioning within a naturalistic setting and does not have the limitations of performance-based tests and environmental effects during the administration. Mahone and Hoffman compared scales of the BRIEF-P and performance-based executive function measures. They showed positive and consistent but nonsignificant correlations between parent-report and performance-based scales (Mahone \& Hoffman, 2007). The subscales of BRIEF-P show adequate to high test-retest reliability and content validity indicating suitability for research purposes (Sherman \& Brooks, 2010).

\section{Attention Deficit/Hyperactivity Problems}

We used the Attention Deficit/Hyperactivity Problem subscale of the Child Behavior Checklist for toddlers $\left(\mathrm{CBCL} / 1 \frac{1}{2}-5\right)$ to acquire a standardized parent report of ADHD-like behavior in children (Achenbach \& Rescorla, 2000). Attention Deficit/Hyperactivity Problem subscale has six items: (a) cannot concentrate, cannot pay attention for long, (b) cannot sit still, restless, or hyperactive, (c) cannot stand waiting, wants everything now, (d) demands must be met immediately (e) gets into everything, and (f) quickly shifts from one activity to another. The $\mathrm{CBCL} / 1 \frac{1}{2}-5$ can be used to evaluate children suspected of having ADHD and determine the extent of a child's problems across a broad spectrum of syndromes (Achenbach \& Ruffle, 2000). The reliability and validity of the Dutch version of CBCL/ $1 \frac{1 / 2}{2}-5$ had been demonstrated previously (Tick, van der Ende, Koot, \& Verhulst, 2007).

In the present study, the CBCL/ $1 \frac{1 / 2}{2} 5$ was completed, in the vast majority, by the mothers when the children were 3 (36.4 \pm 1.0 months) and 5 years (70.5 \pm 2.4 months).

\section{Covariates}

Potential confounders were selected on the basis of background knowledge about the causal structure of the study question (Herba et al., 2010; Peterson et al., $2000,2003)$. Information on date of birth, gender, and birth weight was obtained from midwives and hospital registries. Gestational age at birth was established using the ultrasound examination during pregnancy. Subsequent to brain ultrasound assessment, we measured fronto-occipital head circumference. Parity, maternal age, smoking, and education were assessed by questionnaires at enrollment. Maternal education was defined by the highest completed education and classified as primary (no or only primary education), secondary (lower or intermediate vocational education), and higher education (higher vocational education or university). We used the Brief Symptom Inventory to measure maternal psychopathology during pregnancy (de Beurs, 2004). This is a validated self-report questionnaire with 53 items that define a spectrum of psychiatric disorders. High validity and reliability have been reported for the Dutch translation (de Beurs, 2004). We used the Edinburgh Postnatal Depression Scale, a widely used 10-item self-report scale, to assess symptoms of postnatal emotional distress (Cox, Holden, \& Sagovsky, 1987).

\section{Statistical analysis}

Children with information on one or more brain structures were included in the analyses. The percentages of missing for the outcome variables were between $15 \%$ and $18 \%$. Missing values of the covariates and the 
outcomes were imputed using multiple imputations. Ten copies of the original dataset were generated, with missing values replaced by values randomly generated from the predictive distribution on the basis of the correlation between the variable with missing values and other variables. The analyses were repeated in the original and 10 independent imputed datasets. Effect size and confidence intervals were estimated by taking the average effect size of the 10 imputed datasets considering the uncertainty associated with the missing data (Supporting information Table S1 and S2 present the results of the original dataset). We used independent sample $t$-test and chi-square statistics to explore whether the response was selective.

The executive function and Attention Deficit/Hyperactivity Problem scores were transformed (natural logarithm and square root, respectively) to satisfy the assumptions of normality. For descriptive purposes, we used the 98th percentile of a Dutch norm group as cutoff score to classify children as having behavioral problems within the clinical range (Tick et al., 2007). $Z$ scores were derived for the determinants to allow comparability of the regression coefficients. The associations between brain measurements and executive function or Attention Deficit/Hyperactivity Problem scores were analyzed using multivariable linear regression. To avoid multiple comparisons, we first tested the association of brain structures with the Global Executive Composite score. Consequently, we explored whether any observed effect was accounted for by specific domains of executive function using the five subscales. As meta-analyses showed gender differences in ADHD symptoms (Gershon, 2002), we explored the statistical interaction between gender and brain measures.

We adjusted all analyses for head circumference at the time of ultrasound to ensure that the effects did not reflect the association with head size. The final models were adjusted for child's gender, gestational age at birth, age, and head circumference at the time of ultrasound, maternal age, education, and smoking history. We ran the models additionally adjusted for maternal psychopathology during pregnancy and postnatal emotional distress. The results of the two latter models were reported separately to allow evaluation of the possible effect of adjustment. We applied a Bonferroni adjustment to correct for multiple comparisons of three brain structures with the outcomes.

\section{Results}

The children without successful brain ultrasounds ( $n=100,11.3 \%)$ had a slightly greater birth weight than the included children (mean difference $=126 \mathrm{~g}$, 95\% CI: 17, 234, $p=.02$ ). Nonresponse was not associated with gestational age at birth, parity, maternal age or maternal education. However, mothers of children excluded from the analyses were more likely to have smoked during pregnancy $(21 \%$ vs. $\left.11.8 \% ; \chi^{2}=6.8(2), p=.03\right)$. From 100 children excluded from analyses, follow-up data on the Attention Deficit/Hyperactivity Problems and executive function were available in 78 and 84 individuals, respectively. The scores on Attention Deficit/Hyperactivity Problem did not differ between children included in the analyses and those with unsuccessful ultrasound (mean difference $=-.24,95 \%$ CI: -.80 , .33, $p=.79$ ). Similar nonsignificant differences were observed for executive function scores (data not shown).

As expected, only few children scored above the 98th percentile (clinical range) of a Dutch norm for Attention Deficit/Hyperactivity Problems $(n=10$ at age 3 and $n=22$ at 5 years). Table 1 summarizes the participants' characteristics. Boys had a slightly larger head than girls (mean difference $=.7 \mathrm{~cm}, 95 \%$ CI: .5, .9, $p<.001)$. There was no gender difference in the size of brain structures after covarying for head circumference. The corpus callosum length and fronto-occipital head circumference were correlated, $\quad r=.31 \quad(p<.001)$. The correlation between head circumference and the gangliothalamic ovoid diameter was $r=.52(p<.001)$; that

Table 1 Participants characteristics

\begin{tabular}{|c|c|c|c|}
\hline & $\begin{array}{c}\text { Total valid } \\
\text { observation } \\
(n=784)\end{array}$ & $\begin{array}{c}\text { Boys } \\
(n=401)\end{array}$ & $\begin{array}{c}\text { Girls } \\
(n=383)\end{array}$ \\
\hline \multicolumn{4}{|l|}{ Child } \\
\hline $\begin{array}{l}\text { Gestational age at birth, } \\
\text { week }\end{array}$ & 784 & $40.0 \pm 1.8$ & $40.1 \pm 1.5$ \\
\hline Birth weight, g & 784 & $3536 \pm 535$ & $3468 \pm 509$ \\
\hline Firstborn, \% & 782 & 63.1 & 60.1 \\
\hline Global Executive & 655 & $88.4 \pm 17.1$ & $82.5 \pm 13.5$ \\
\hline Composite Problem Score & & & \\
\hline $\begin{array}{l}\text { Attention Deficit/ } \\
\text { Hyperactivity } \\
\text { Problem scores, } 3 \text { years }\end{array}$ & 649 & $2.6 \pm 2.1$ & $2.8 \pm 2.2$ \\
\hline $\begin{array}{l}\text { Attention Deficit/ } \\
\text { Hyperactivity } \\
\text { Problem scores, } 5 \text { years }\end{array}$ & 667 & $3.0 \pm 2.5$ & $2.3 \pm 2.2$ \\
\hline \multicolumn{4}{|c|}{ Brain ultrasound measurements } \\
\hline Age, week & 784 & $6.8 \pm 1.8$ & $6.9 \pm 2.0$ \\
\hline $\begin{array}{l}\text { Fronto-occipital head } \\
\text { circumference, } \mathrm{cm}\end{array}$ & 753 & $39.0 \pm 1.4$ & $38.3 \pm 1.4$ \\
\hline Corpus callosum & 784 & $4.6 \pm 0.3$ & $4.7 \pm 0.3$ \\
\hline length, $\mathrm{cm}$ & & & \\
\hline $\begin{array}{l}\text { Gangliothalamic ovoid } \\
\text { diameter, } \mathrm{cm}\end{array}$ & 784 & $4.3 \pm 0.2$ & $4.3 \pm 0.2$ \\
\hline $\begin{array}{l}\text { Cerebral ventricular } \\
\text { volume, } \mathrm{ml}\end{array}$ & 744 & $1.0 \pm 0.8$ & $0.9 \pm 0.7$ \\
\hline \multicolumn{4}{|l|}{ Mother } \\
\hline $\begin{array}{l}\text { Age at enrollment, year } \\
\text { Education, \% }\end{array}$ & 784 & $31.6 \pm 4.1$ & $32.1 \pm 3.7$ \\
\hline Primary & 773 & 10.6 & 10.1 \\
\hline Secondary & & 53.3 & 49.9 \\
\hline High & & 36.1 & 40.1 \\
\hline \multicolumn{4}{|l|}{ Smoking, \% } \\
\hline Never & 782 & 79.5 & 79.6 \\
\hline Until pregnancy & & 7.0 & 10.5 \\
\hline \multicolumn{4}{|l|}{ was known } \\
\hline $\begin{array}{l}\text { Continued during } \\
\text { pregnancy }\end{array}$ & & 13.5 & 9.9 \\
\hline $\begin{array}{l}\text { Psychopathology during } \\
\text { pregnancy }\end{array}$ & 731 & $0.20 \pm 0.3$ & $0.17 \pm 0.2$ \\
\hline
\end{tabular}

Numbers are mean $\pm S D$ unless otherwise is indicated. 
between head circumference and the cerebral ventricular volume was $r=.27(p<.001)$.

There was a substantial correlation between Attention Deficit/Hyperactivity Problem scores at 5 years and domains of executive function: inhibition: $r=.58$, shifting: $r=.21$, emotional control: $r=$ .36 , working memory: $r=.49$, planning/organization: $r=.38$, and the Global Executive Composite score: $r=.53$. All correlations were significant at $p<.001$.

Table 2 presents the associations of postnatal brain measurements with executive function and Attention Deficit/Hyperactivity Problem scores in preschoolers. A smaller corpus callosum length predicted a higher Global Executive Composite problem score (adjusted $B=-.02,95 \%$ CI: -.04 , -.004 , Bonferroni corrected $p=.05$ ). In contrast, the gangliothalamic ovoid diameter and the cerebral ventricular volume were not related to executive function (adjusted $B=.002,95 \% \mathrm{CI}:-.02, .032, p=$ .88 , and adjusted $B=.004,95 \%$ CI: $-.02, .03, p=$ .73 , respectively). Next, we explored the association between brain measurement and Attention Deficit/ Hyperactivity Problem scores. The corpus callosum length and the gangliothalamic ovoid diameter were not related to Attention Deficit/Hyperactivity Problem scores at 3 years (adjusted $B=-.03,95 \% \mathrm{CI}$ : $-.09, .03, p=.40$ and adjusted $B=.02,95 \% \mathrm{CI}$ : $-.05, .09, p=.65$, respectively). The corpus callosum length and the gangliothalamic ovoid diameter were associated with Attention Deficit/Hyperactivity Problems at 3 and 5 years. However, after adjustment for confounders, the corpus callosum length and gangliothalamic ovoid diameter did not predict Attention Deficit/Hyperactivity Problem scores at 5 years $(B=-.04,95 \%$ CI: $-.11, .02, p=.21$; and $B=-.02,95 \%$ CI: $-.10, .05, p=.54$, respectively). The cerebral ventricular volume was not related to Attention Deficit/Hyperactivity Problems.
In further analyses, we explored the associations between the corpus callosum length and five domains of executive function to see which domain accounted for the observed association (Table 3). A smaller corpus callosum length predicted a higher problem score on inhibition (adjusted $B=-.02,95 \%$ CI: $-.04,-.002, p=.03$ ) and emotional control (adjusted $B=-.02,95 \%$ CI: $-.04, .00, p=.05)$. There was no significant interaction between gender and brain structures in predicting Attention Deficit/ Hyperactivity Problems and executive functioning (data not shown).

To explore whether postnatal emotional stress affects the relation of postnatal corpus callosum length with executive function or the Attention Deficit/Hyperactivity Problems, we adjusted all models for maternal postnatal emotional stress. After adjustment, the corpus callosum length was related to the Global Executive Composite scores ( $B$ additionally adjusted for maternal emotional stress $=-.02,95 \%$ CI: $-.04,-.002, p=.03)$. The relation between the corpus callosum length and the Attention Deficit/Hyperactivity Problems at 3 and 5 years remained nonsignificant after additional adjustment.

Next, we reran the analyses between the corpus callosum length and executive function additionally adjusted for maternal psychopathology during pregnancy. When adjusted for maternal psychopathology, the association between the corpus callosum length and the Global Executive Composite scores remained unchanged $(B=-.02,95 \% \mathrm{CI}:-.05$, $.00, p=.05)$.

\section{Discussion}

This study presents the population-based prospective data of a large number of infants followed until preschool age. We found an association between a

Table 2 Postnatal brain ultrasound measurements, executive functioning, and attention deficit/hyperactivity problems at preschool age

\begin{tabular}{|c|c|c|c|c|c|c|c|c|c|}
\hline \multirow[b]{2}{*}{ Ultrasound measurements (per $S D)^{a}$} & \multicolumn{3}{|c|}{$\begin{array}{c}\text { Executive functioning at } \\
4 \text { years }\end{array}$} & \multicolumn{3}{|c|}{$\begin{array}{l}\text { Attention Deficit/Hyperactiv- } \\
\text { ity Problem Scores at } 3 \text { years }\end{array}$} & \multicolumn{3}{|c|}{$\begin{array}{c}\text { Attention Deficit/Hyperac- } \\
\text { tivity Problem Scores at } \\
5 \text { years }\end{array}$} \\
\hline & $\beta$ & $B(95 \% \mathrm{CI})$ & $p$ & $\beta$ & $B(95 \% \mathrm{CI})$ & $p$ & $\beta$ & $B(95 \% \mathrm{CI})$ & $p$ \\
\hline \multicolumn{10}{|l|}{ Corpus callosum length } \\
\hline Unadjusted & -.10 & $-.02(-.04,-.005)$ & .01 & -.08 & $-.06(-.12,-.004)$ & .04 & -.10 & $-.08(-.15,-.02)$ & .01 \\
\hline Adjusted & -.09 & $-.02(-.04,-.004)$ & .02 & -.03 & $-.03(-.09, .03)$ & .40 & -.05 & $-.04(-.11, .02)$ & .21 \\
\hline \multicolumn{10}{|l|}{ Gangliothalamic ovoid diameter } \\
\hline Unadjusted & -.04 & $-.01(-.03, .01)$ & .43 & -.08 & $-.06(-.12,-.003)$ & .04 & -.08 & $-.07(-.13,-.01)$ & .03 \\
\hline Adjusted & -.01 & $.002(-.02, .03)$ & .88 & .02 & $.02(-.05, .09)$ & .65 & -.03 & $-.02(-.10, .05)$ & .54 \\
\hline \multicolumn{10}{|l|}{ Cerebral ventricular volume } \\
\hline Unadjusted & .01 & $.002(-.02, .02)$ & .87 & .01 & $.003(-.06, .07)$ & .92 & .01 & $.01(-.06, .08)$ & .79 \\
\hline Adjusted & .02 & $.004(-.02, .03)$ & .73 & .03 & $.03(-.04, .09)$ & .41 & .02 & $.02(-.05, .08)$ & .65 \\
\hline
\end{tabular}

Models were adjusted for child's gender, gestational age at birth, age, and head circumference at the time of brain ultrasound, maternal age, education, and smoking during pregnancy.

The B's are not interpretable since the mathematically transformed scores were used in the analyses.

${ }^{\mathrm{a}} \mathrm{Z}$ scores were derived to make regression coefficient comparable. 
Table 3 Postnatal corpus callosum length and executive function at 4 years

\begin{tabular}{|c|c|c|c|c|c|c|c|c|c|c|}
\hline \multirow{3}{*}{\multicolumn{2}{|c|}{ Ultrasound measurements (per $S D)^{\mathrm{a}}$}} & \multicolumn{9}{|c|}{ Executive function } \\
\hline & & \multicolumn{3}{|c|}{ Inhibition } & \multicolumn{3}{|c|}{ Shifting } & \multicolumn{3}{|c|}{ Emotional control } \\
\hline & & $\beta$ & $B(95 \% \mathrm{CI})$ & $p$ & $\beta$ & $B(95 \% \mathrm{CI})$ & $p$ & $\beta$ & $B(95 \% \mathrm{CI})$ & $p$ \\
\hline \multicolumn{11}{|c|}{ Corpus callosum length } \\
\hline Unadjusted & & -.10 & $-.02(-.04,-.004)$ & .02 & -.04 & $-.01(-.03, .01)$ & .27 & -.08 & $-.02(-.04,-.001)$ & .05 \\
\hline \multirow[t]{3}{*}{ Adjusted } & & -.09 & $-.02(-.04,-.002)$ & .03 & -.07 & $-.02(-.03, .004)$ & .12 & -.08 & $-.02(-.04, .00)$ & .05 \\
\hline & \multicolumn{5}{|c|}{ Working memory } & \multicolumn{5}{|c|}{ Planning/organization } \\
\hline & $\beta$ & & $B(95 \% \mathrm{CI})$ & & $p$ & $\beta$ & & $B(9$ & $5 \%$ CI) & $p$ \\
\hline \multicolumn{11}{|c|}{ Corpus callosum length } \\
\hline Unadjusted & -.10 & -.0 & $2(-.04,-.01)$ & & .01 & -.08 & \multirow{2}{*}{\multicolumn{3}{|c|}{$\begin{array}{l}-.02(-.03,-.002) \\
-.01(-.03, .002)\end{array}$}} & .03 \\
\hline Adjusted & -.07 & -.0 & $1(-.03, .001)$ & & .07 & -.07 & & & & .10 \\
\hline
\end{tabular}

Models were adjusted for child's gender, gestational age at birth, age, and head circumference at the time of brain ultrasound, maternal age, education, and smoking during pregnancy.

The B's are not interpretable since the mathematically transformed scores were used in the analyses.

${ }^{a} Z$ scores were derived to make regression coefficient comparable.

smaller corpus callosum length in infancy and impaired executive function at 4 years. This association was accounted for by higher scores of inhibition and emotional control, indicating more problems. However, we found no indication for a relation between infant brain structures and Attention Deficit/Hyperactivity Problems.

Our study provides no support for an association between postnatal corpus callosum length and Attention Deficit/Hyperactivity Problems at preschool years. This is inconsistent with findings of previous studies in children with clinical diagnosis of ADHD showing abnormalities in the corpus callosum size (Hutchinson et al., 2008; Seidman, Valera, $\&$ Makris, 2005). In our general population sample, although some children showed symptoms of inattention or hyperactivity, the degree of problem behaviors were generally well below the clinical threshold. Furthermore, as opposed to the abovementioned studies with concurrent assessment of brain structures and ADHD symptoms, our study had a prospective design. Postnatal brain measurements precede the Attention Deficit/Hyperactivity symptoms. Therefore, any interpretation of these negative findings should be done cautiously.

We found that a smaller corpus callosum length during infancy predicted poorer executive functioning, in particular, inhibition and emotional control. This is compatible with findings of studies in preterm or very low birth weight infants that show corpus callosum abnormalities predict executive dysfunction in all domains (Woodward et al., 2011). The corpus callosum length in the postnatal period largely reflects the development of this structure during fetal life. However, in our relatively healthy sample of neonates, indicators of prematurity such as birth weight did not account for the relation between postnatal corpus callosum length and executive dysfunction. A shorter corpus callosum length may reflect a global reduction in white matter size, either primary or secondary to gray matter size alternation. The length of corpus callosum is an indicator of axon numbers and extent of myelination, both crucial for information transfer and connectivity in the brain. In addition, variations in the corpus callosum size may influence the downstream pruning in the very plastic brain during infancy, for example, the fibers connected to the corpus callosum may be more likely to be pruned. Although this is speculative, the possible cascade of events in the brain during early development preceding the symptoms of ADHD will increase our understanding of pathophysiology underlying the disorder.

In our sample, postnatal gangliothalamic ovoid diameter was not associated with executive dysfunction or Attention Deficit/Hyperactivity Problem in preschoolers. This is in contrast with previous findings on the key role of prefrontal-basal gangliathalamic loop in executive dysfunction of ADHD children (Seidman et al., 2005). However, the explanation may lie in the fact that different subcircuits are responsible for symptoms of ADHD (Ivanov et al., 2010). Thus, the absence of a significant association may derive from the fact that ultrasound is not the optimal technique to detect structural variations if abnormalities are restricted to the small substructures. In addition, after postnatal age, through the process of learning, the brain undergoes changes in numbers of neurons and synapses; which may explain the absence of expected variations during infancy.

In our study, cerebral ventricular volume was not significantly associated with executive function and Attention Deficit/Hyperactivity Problems. Previous longitudinal studies in preterm children showed that ventricular enlargement during infancy predicts executive function at 4 years (Woodward et al., 2011). However, epidemiological studies in the general pop- 
ulation demonstrated that the size of the ventricular volume within the normal range is determined by maturation during fetal life (Gilmore et al., 1998). Cerebral ventricular volume in healthy newborns and ventricular enlargement in the clinical population may have a different underlying pathophysiology. Furthermore, prior studies reveal that the increase in cerebral ventricular volume, as seen in normal children with increase in age, diminishes in ADHD children (Castellanos et al., 1996). This may indicate that the growth pattern rather than the size of ventricles is predictive of future behavior impairment.

Findings from anatomical MRI studies in ADHD children provide evidence for involvement of different brain structures (Castellanos, 2002; Seidman et al., 2005). However, findings are consistent only for involvement of striatum (Ellison-Wright, Ellison-Wright, \& Bullmore, 2008). Results are mixed regarding other brain regions. For example, children with ADHD do not differ from controls in absolute corpus callosum size (Castellanos et al., 1996), despite different growth trajectories of corpus callosum (Gilliam et al., 2011), or whole thalamic volumes are not different in ADHD children and in controls, although mapping of the thalamic surface showed that ADHD children had smaller regional volumes bilaterally than controls (Ivanov et al., 2010). These findings imply that defining a robust neuroanatomical marker for ADHD is complex and may not be easy to achieve.

Although our study has several strengths such as large population-based sample, the unique prospective design, and measurement of brain structures in infants, we were faced with certain methodological limitations. First, we measured the brain structures using cranial ultrasound that cannot provide detailed images of specific substructures in the brain. Although cranial ultrasound in neonates has limited value in reflecting variations in the brain structures compared with MRI (Anderson et al., 2004), it is a reliable, noninvasive, and costeffective technique to image infants and can be used in follow-up studies of healthy infants (Riccabona, 2005). Second, we measured the corpus callosum across the entire length; whereas the corpus callosum area may be a better indicator of size. The corpus callosum area cannot be measured reliably by cranial ultrasound. However, studies have reported a good correlation between the corpus callosum length and thinness (Anderson, Laurent, Woodward, $\&$ Inder, 2006). Third, we used parent report of executive function and Attention Deficit/Hyperactivity Problems. Parents may be affected by many factors in reporting child's behavior which introduce bias (Seifer, 2003). However, parent's reports on child behavior are based on their observation in a naturalistic setting over a long period, and serves as an inexpensive and easy-to-administer method suitable for research purposes. Fourth, we did not have a clinical diagnosis of ADHD in our sample of children. However, it is very likely that the symptoms of hyperactivity or inattention during preschool period stay persistent to older age, when ADHD can be validly diagnosed in children (Taylor \& SonugaBarke, 2010). Considering the fact that we had a population-based sample, with relatively small numbers of children meeting criteria for clinical diagnosis of ADHD, and used ultrasound as measurement technique for brain structures, null findings regarding attention deficit/hyperactivity problems do not rule out a possible relation between early structural differences in the brain and ADHD. On the other hand, the association of the corpus callosum length with executive functioning shows that the study was well powered and the measures were sensitive enough to detect an expected association.

\section{Supporting information}

Additional Supporting Information may be found in the online version of this article:

Table S1. Postnatal brain ultrasound measurements, executive functioning, and attention deficit/ hyperactivity problems at preschool age (Complete case analyses).

Table S2. Postnatal corpus callosum length and executive function at 4 years (Complete-case analyses).

Please note: Wiley-Blackwell are not responsible for the content or functionality of any supporting materials supplied by the authors. Any queries (other than missing material) should be directed to the corresponding author for the article.

\section{Acknowledgement}

The Generation $\mathrm{R}$ study is conducted by Erasmus Medical Center Rotterdam in close collaboration with the faculty of Social Sciences of Erasmus University Rotterdam, the Municipal Health Service Rotterdam area, the Rotterdam Homecare Foundation and the Stichting Trombosedienst \& Artsenlaboratorium Rijnmond (STAR), Rotterdam. We gratefully acknowledge the contribution of general practitioners, hospitals, midwifes and pharmacies in Rotterdam. The first phase of Generation R was supported by Erasmus Medical Centre Rotterdam, the Erasmus University Rotterdam, and the Netherlands Organization for Health Research and Development (ZonMw 10.000.1003). Dr. Frank C. Verhulst is the contributing editor of the Achenbach System of Empirically Based Assessment, from which he receives remuneration. For the other authors, no competing financial interest exists.

\section{Correspondence}

Henning Tiemeier, Department of Child and Adolescent Psychiatry, Erasmus MC-Sophia Children's Hospital, P.O. Box 2060, 3000 CB Rotterdam, the Netherlands; Email: h.tiemeier@erasmusmc.nl 


\section{Key points}

- In the present population-based study, there was a substantial association between attention deficit/hyperactivity and executive function scores in preschoolers.

- There was a relation between the corpus callosum length and executive function independent of head circumference and other confounders.

- This association was accounted for by higher problem scores on inhibition and emotional control.

- There was no relation between the size of any brain structure measurements in infancy and attention deficit/ hyperactivity at preschool age.

- The present prospective study of healthy infants shows that individual differences in particular brain structures can predict the impairments in inhibition or emotional control in preschool age, even though few children had symptoms above the clinical threshold of ADHD.

\section{References}

Achenbach, T.M., \& Rescorla, L.A. (2000). Manual for ASEBA preschool forms and profiles. Burlington, VT: University of Vermont, Research Center for Children, Youth, and Families.

Achenbach, T.M., \& Ruffle, T.M. (2000). The child behavior checklist and related forms for assessing behavioral/emotional problems and competencies. Pediatrics in Review/ American Academy of Pediatrics, 21, 265-271.

Anderson, N.G., Laurent, I., Woodward, L.J., \& Inder, T.E. (2006). Detection of impaired growth of the corpus callosum in premature infants. Pediatrics, 118, 951-960.

Anderson, N.G., Warfield, S.K., Wells, S., Spencer, C., Balasingham, A., Volpe, J.J., \& Inder, T.E. (2004). A limited range of measures of 2-D ultrasound correlate with 3-D MRI cerebral volumes in the premature infant at term. Ultrasound in medicine \& biology, 30, 11-18.

de Beurs, E. (2004). Brief Symptom Inventory, handleiding. Leiden: PITS.

Castellanos, F.X. (2002). Anatomic magnetic resonance imaging studies of attention-deficit/hyperactivity disorder. Dialogues in Clinical Neuroscience, 4, 444-448.

Castellanos, F.X., Giedd, J.N., Marsh, W.L., Hamburger, S.D. Vaituzis, A.C., Dickstein, D.P., ... \& Rapoport, J.L. (1996). Quantitative brain magnetic resonance imaging in attentiondeficit hyperactivity disorder. Archives of general psychiatry, 53, 607-616.

Clark, D.L., Boutros, N.N., \& Mendez, M.F. (2010). The brain and behavior: An introduction to behavioral neuroanatomy (3rd edn). Cambridge: Cambridge University Press.

Cox, J.L., Holden, J.M., \& Sagovsky, R. (1987). Detection of postnatal depression. Development of the 10-item Edinburgh Postnatal Depression Scale. British Journal of Psychiatry, 150, 782-786.

Ducharme, S., Hudziak, J.J., Botteron, K.N., Albaugh, M.D., Nguyen, T.-V., Karama, S., ... \& Brain Development Cooperative Group (2012). Decreased regional cortical thickness and thinning rate are associated with inattention symptoms in healthy children. Journal of the American Academy of Child and Adolescent Psychiatry, 51, 18-27.

Ellison-Wright, I., Ellison-Wright, Z., \& Bullmore, E. (2008). Structural brain change in attention deficit hyperactivity disorder identified by meta-analysis. BMC Psychiatry, 8, 51.

Gershon, J. (2002). A meta-analytic review of gender differences in ADHD. Journal of attention disorders, 5, 143-154.

Gilliam, M., Stockman, M., Malek, M., Sharp, W., Greenstein, D., Lalonde, F., ... \& Shaw, P. (2011). Developmental trajectories of the corpus callosum in attention-deficit/ hyperactivity disorder. Biological psychiatry, 69, 839-846.

Gilmore, J.H., van Tol, J., Kliewer, M.A., Silva, S.G., Cohen, S.B., Hertzberg, B.S., \& Chescheir, N.C. (1998). Mild ventri- culomegaly detected in utero with ultrasound: Clinical associations and implications for schizophrenia. Schizophrenia research, 33, 133-140.

Gioia, G.A., Espy, K.A., \& Isquith, P.K. (2003). Behavior Rating Inventory of executive function preschool version (brief-p), professional manual. Lutz, FL: Psychological Assessment Resources Inc. (PAR).

Hendren, R.L., De Backer, I., \& Pandina, G.J. (2000). Review of neuroimaging studies of child and adolescent psychiatric disorders from the past 10 years. Journal of the American Academy of Child and Adolescent Psychiatry, 39, 815-828.

Herba, C.M., Roza, S.J., Govaert, P., van Rossum, J., Hofman, A., Jaddoe, V., ... \& Tiemeier, H. (2010). Infant brain development and vulnerability to later internalizing difficulties: The Generation $\mathrm{R}$ study. Journal of the American Academy of Child and Adolescent Psychiatry, 49, 10531063.

Hutchinson, A.D., Mathias, J.L., \& Banich, M.T. (2008). Corpus callosum morphology in children and adolescents with attention deficit hyperactivity disorder: A meta-analytic review. Neuropsychology, 22, 341-349.

Ivanov, I., Bansal, R., Hao, X., Zhu, H., Kellendonk, C., Miller, L., ... \& Peterson, B.S. (2010). Morphological abnormalities of the thalamus in youths with attention deficit hyperactivity disorder. The American journal of psychiatry, 167, 397-408.

Jaddoe, V.W., van Duijn, C.M., van der Heijden, A.J., Mackenbach, J.P., Moll, H.A., Steegers, E.A., ... \& Hofman, A. (2010). The Generation R Study: Design and cohort update 2010. European journal of epidemiology, 25, 823-841.

Kimura, M., Minamimoto, T., Matsumoto, N., \& Hori, Y. (2004). Monitoring and switching of cortico-basal ganglia loop functions by the thalamo-striatal system. Neuroscience Research, 48, 355-360.

Mahone, E.M., \& Hoffman, J. (2007). Behavior ratings of executive function among preschoolers with ADHD. The Clinical Neuropsychologist, 21, 569-586.

Naidich, T.P., Gusnard, D.A., \& Yousefzadeh, D.K. (1985). Sonography of the internal capsule and basal ganglia in infants: 1. Coronal sections. AJNR. American journal of neuroradiology, 6, 909-917.

Naidich, T.P., Yousefzadeh, D.K., Gusnard, D.A., \& Naidich, J.B. (1986). Sonography of the internal capsule and basal ganglia in infants. Part II. Localization of pathologic processes in the sagittal section through the caudothalamic groove. Radiology, 161, 615-621.

Peterson, B.S., Anderson, A.W., Ehrenkranz, R., Staib, L.H., Tageldin, M., Colson, E., ... \& Ment, L.R. (2003). Regional brain volumes and their later neurodevelopmental correlates in term and preterm infants. Pediatrics, 111, 939-948.

Peterson, B.S., Vohr, B., Staib, L.H., Cannistraci, C.J., Dolberg, A., Schneider, K.C., ... \& Ment, L.R. (2000). Regional brain volume abnormalities and long-term cognitive out- 
come in preterm infants. Journal of the American Medical Association, 284, 1939-1947.

Riccabona, M. (2005). Pediatric three-dimensional ultrasound Basics and potential clinical value. Clinical imaging, 29, 1-5.

Roza, S.J., Govaert, P.P., Vrooman, H.A., Lequin, M.H., Hof man, A., Steegers, E.A., ... \& Tiemeier, H. (2008). Foetal growth determines cerebral ventricular volume in infants The Generation R Study. Neuroimage, 39, 1491-1498.

Rubia, K. (2005). The study of neurodevelopmental psychiatric disorders using magnetic resonance imaging. Psychiatry, 4, 6-10.

Santhouse, A.M., Ffytche, D.H., Howard, R.J., Williams, S.C., Stewart, A.L., Rooney, M., ... \& Murray, R.M. (2002). The functional significance of perinatal corpus callosum damage: An fMRI study in young adults. Brain, 125, 1782-1792.

Seidman, L.J., Valera, E.M., \& Makris, N. (2005). Structural brain imaging of attention-deficit/hyperactivity disorder. Biological Psychiatry, 57, 1263-1272.

Seifer, R. (2003). Twin studies, biases of parents, and biases of researchers. Infant Behavior \& Development, 26, 115-117.

Sherman, E.M.S., \& Brooks, B.L. (2010). Behavior rating inventory of executive function - Preschool version (BRIEFP): Test review and clinical guidelines for use. Child Neuropsychology, 16, 503-519.

Stewart, A.L., Rifkin, L., Amess, P.N., Kirkbride, V., Townsend, J.P., Miller, D.H., ... \& Murray, R.M. (1999). Brain structure and neurocognitive and behavioural function in adolescents who were born very preterm. Lancet, 353, 1653-1657.
Taylor, E., \& Sonuga-Barke, E. (2010). Disorders of attention and activity. In M. Rutter, D. Bishop, D. Pine, S. Scott, J.S. Stevenson, E.A. Taylor, \& A. Thapar (Eds.), Rutter's child and adolescent psychiatry (pp. 521-542). Malden, MA: Blackwell Publishing.

Tick, N.T., van der Ende, J., Koot, H.M., \& Verhulst, F.C. (2007). 14-year changes in emotional and behavioral problems of very young Dutch children. Journal of the American Academy of Child and Adolescent Psychiatry, 46, 13331340 .

Willcutt, E.G., Doyle, A.E., Nigg, J.T., Faraone, S.V., \& Pennington, B.F. (2005). Validity of the executive function theory of attention-deficit/hyperactivity disorder: A metaanalytic review. Biological Psychiatry, 57, 1336-1346.

Woodward, L.J., Clark, C.A., Pritchard, V.E., Anderson, P.J., \& Inder, T.E. (2011). Neonatal white matter abnormalities predict global executive function impairment in children born very preterm. Developmental Neuropsychology, 36, 22-41.

Yakovlev, P.I., \& Lecours, A.R. (1967). The myelogenetic cycles of regional maturation of the brain. In A. Minkowski (Ed.), Regional development of the brain in early life (pp. 3-70). Oxford: Blackwell Scientific.

Accepted for publication: 18 June 2012

Published online: 28 August 2012 